\title{
Effect of air stacking training on pulmonary function, respiratory strength and peak cough flow in persons with cervical spinal cord injury
}

\author{
Sang-Kyun $\mathrm{An}^{\mathrm{a}}{ }^{\mathrm{a}}$, Won-Seob Shin ${ }^{\mathrm{b}}$ \\ aDepartment of Physical Therapy, Graduate School of Daejeon University, Daejeon, Republic of Korea \\ ${ }^{b}$ Department of Physical Therapy, College of Health and Medical Science, Daejeon University, Daejeon, Republic of Korea
}

Objective: This study investigated the effects of air stacking training (AST) on pulmonary function, respiratory strength, and peak cough flow (PCF) in persons with cervical spinal cord injury (CSCI).

Design: Randomized controlled trial.

Methods: A total of 24 persons with CSCI were randomly allocated to the AST group $(n=12)$ or the incentive spirometry training (IST) group ( $\mathrm{n}=12)$. Patients with CSCI received AST or IST for 15 minutes, with 3 sessions per week for 4 weeks, and all groups performed basic exercises for 15 minutes. In the AST group, after the subject inhaled the maximal amount of air as best as possible, the therapist insufflated additional air into the patient's lung using an oral nasal mask about 2-3 times. In the IST group, patients were allowed to hold for three seconds at the maximum inspiration and then to breathe. The pre and post-tests measured forced vital capacity (FVC), forced expiratory volume one at second (FEV1), maximal expiratory pressure (MEP), maximal inspiratory pressure (MIP) and PCF.

Results: Both groups showed significant improvements in FVC, FEV1, MEP, MIP and PCF values after training $(p<0.05)$. The FVC in the post-test and the mean change of FVC, FEV1, MIP were significantly higher in the AST group than the IST group $(p<0.05)$.

Conclusions: The findings of this study suggested that AST significantly improved pulmonary function, respiratory strength, and PCF in persons with CSCI. Therefore, AST should be included in respiratory rehabilitation programs to improve coughing ability, pulmonary function and respiratory muscle strength.

Key Words: Breathing exercises, Spinal cord injuries, Maximal respiratory pressures

\section{Introduction}

Respiratory system complications such as pneumonia, atelectasis, pleural effusion, sleep disturbance or dyspnea are present in 50\%-67\% of persons with cervical spinal cord injury (CSCI) [1]. The death rate is $47 \%$ higher than that of the general population [2]. CSCI patients are reported to have a gradual decrease in inspiratory volume and expiratory reserve volume compared to thoracic and lumbar-level spinal cord injury (SCI) patients [3]. Respiratory muscle damage in CSCI patients results in damage to respiratory muscle function and a reduction in lung capacity [4]. CSCI patients have a basic form of restrictive pulmonary disease from direct respiratory weakness due to inspiratory and respiratory muscle paralysis and increased diaphragmatic fatigue [5]. Thus, restricted respiration patterns and reduced lung capacity of CSCI patients can develop into respiratory problems [6]. In addition, the shortened diaphragm due to loss of tone in paralyzed abdominal muscles causes the upper thorax to be displaced inward, causing in-

Received: 23 October, 2018 Revised: 16 November, 2018 Accepted: 17 November, 2018

Corresponding author: Won-Seob Shin (ORCID https://orcid.org/0000-0002-6515-7020)

Department of Physical Therapy, College of Health and Medical Science, Daejeon University, 62 Daehak-ro, Dong-gu, Daejeon 34520, Republic of Korea Tel: 82-42-280-2290 Fax: 82-42-280-2295 E-mail: shinws@dju.kr

(c) This is an Open-Access article distributed under the terms of the Creative Commons Attribution Non-Commercial License (http://creativecommons.org/licenses/ by-nc/4.0) which permits unrestricted non-commercial use, distribution, and reproduction in any medium, provided the original work is properly cited.

Copyright (๑) 2018 Korean Academy of Physical Therapy Rehabilitation Science 
efficient intake and respiratory dynamics, increasing the consumption of oxygen and reducing the elasticity of the chest wall [7]. Reduced elasticity, inefficient cough and hypersecretion of mucus result in insufficient removal of mucus [8].

Proper removal of sputum from CSCI patient is an important function for the prevention of atelectasis and pneumonia [9]. CSCI patients cannot inhale a sufficient amount of air due to weakness of the inspiratory muscle and cannot effectively cough because they cannot compress the thoracoabdominal cavity due to weakness of the expiratory muscle $[10,11]$. In order to cough effectively, sufficient air should be inhaled and the airway should contract normally and increase the intrathoracic pressure sufficiently [12]. Before coughing, lungs and chest compliance should be maintained shortly after injury using manual inhalation of large quantities of air to ensure adequate intake of air volume [13].

Intermittent positive pressure ventilation [14] and air stacking [10] are used clinically for passive and active lung insufflation for CSCI patients. Air stacking is simpler, cheaper, and less expensive to maintain than intermittent positive pressure ventilation [15-17]. When air stacking exercise was applied to patients with neuromuscular disease, the maximal insufflation capacity of the lungs increased and the peak cough flow (PCF) increased $[13,18]$. When air stacking exercise was applied to CSCI patients, the PCF was increased to more than $160 \mathrm{~L} / \mathrm{min}$, which is the normal range, when the PCF was measured by combining abdominal compression after air stacking [17].

Thus, air stacking training (AST) is needed as a method to maintain and increase lung capacity in CSCI patient restrictive pulmonary disease as well as methods for sputum release. However, there is a lack of studies on AST for CSCI patients, and most of them have immediate effects through cross-sectional studies and previous studies have focused on the immediate effects on pulmonary function and PCF through single air stacking for coughing. The purpose of this study was to propose a respiratory rehabilitation program for CSCI patients by examining the effect of AST on pulmonary function, respiratory muscle strength, and PCF.

\section{Methods}

\section{Participants}

Twenty-four CSCI patients who understood the details of the study consented to participate. The inclusion criteria were SCI level C4-C7 within 1 year of initial CSCI, ability to understand instructions, first admission to hospital and normal glottis function without dysphagia, do not have accompanying injuries such as deformation of the rib cage or fracture of the rib before or in the past, patients with a diagnosis of restrictive pulmonary disease with forced vital capacity (FVC) $<80 \%$. Patients were excluded if they had concomitant intrinsic lung diseases, could not hold their breath due to vocal cord paralysis, were intubated or had a tracheostomy, or took medications that affected pulmonary function. All of the protocols used in this study were approved by Daejeon University. Before participation, the procedures, risks, and benefits were explained to all the participants who provided their informed consent. Ethical approval was obtained to commence from Daejeon University Institutional Review Board (IRB No. 1040647-201806-HR023-01).

\section{Intervention}

Twenty-four CSCI patients were randomly divided into two groups, the AST group and the incentive spirometry training (IST) group. Two group members had received training three sessions a week for a total of twelve times for four weeks and performed basic therapeutic exercises (inspiratory muscle strengthening exercise) after intervention.

\section{Air stacking training}

The patient was comfortably placed in a sitting posture and a mask was attached to a manual resuscitator (Ambu bag; Hudson respiratory care Inc., Temecula, CA, USA) to allow simultaneous breathing with the nose and mouth. After the subject inhales the maximal amount of air as best as possible, the therapist insufflates additional air into the patient's lungs using an oral nasal mask about 2-3 times. The subject who inhaled additional air started to exhale the moment that therapist removed mask from the subject. At that time, therapist instructed to breathe slowly until the air was completely discharged through the mouth (Figure 1). This training was repeated 15 times per set, and 3 set were performed for 15 minutes [13].

\section{Incentive spirometry training}

The patient held the incentive spirometer (Coach 2 device; Smiths medical international Ltd., Minneapolis, MN, USA) in sitting position and breathes as deeply as possible at a constant flow rate. The patient was allowed to hold for three seconds at the maximum inspiration and then to 


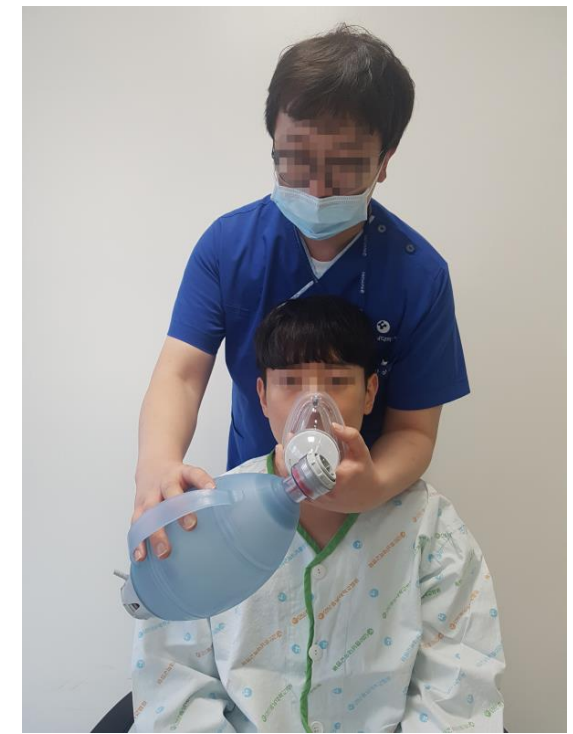

Figure 1. Air stacking training.

breathe (Figure 2). The deep breathing process was repeated 15 times per set, and 3 sets were performed for 15 minutes [18].

\section{Basic therapeutic exercise (inspiratory muscle strength- ening exercise)}

Both groups performed inspiratory muscle strengthening exercise using an adjustable pressure threshold loading device (Threshold inspiratory muscle trainer device; Philips Respironics, Bend, OR, USA) after intervention. Both groups in the intake muscle training group started training at $40 \%$ of the maximal inspiratory pressure (MIP) after measuring the initial MIP. The training intensity was increased by $5 \%-10 \%$ in a stepwise manner based on a one week cycle, and was trained with a maximum of $60 \%$ intensity (Figure 3 ). Exercise was performed and each session lasted for $15 \mathrm{mi}-$ nutes, consisted of a cycle of 3 minutes inspiratory training with a pressure threshold loading device, 1-minute of rest period, and then a repetition of five cycles [19].

\section{Outcome measures}

\section{Pulmonary function}

The pulmonary function of the patient was measured using a spirometer (Master screen Pneumo; CareFusion, Höchberg, Germany) in sitting position. The subject was encouraged to breathe in as much as one could, and then breathe out as fast as possible. The FVC and forced expiratory one at second (FEV1) were measured at that time. This process was repeated at least three times. The highest

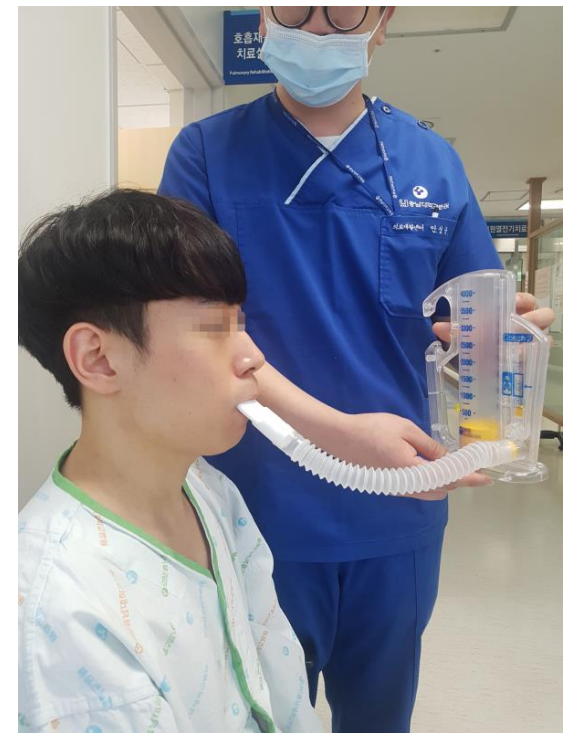

Figure 2. Incentive spirometry training.

value was selected as the FVC and FEV1 [20].

\section{Respiratory strength}

Maximal respiratory pressure and reflecting respiratory muscle strength was measured using a mouth pressure meter (Micro RPM; Micro Medical Ltd., Rochester, England). To measure maximal expiratory pressure (MEP), subjects performed maximal expiratory effort after maximal inspiration. MIP was measured by exerting maximal inspiratory effort after maximal expiration. To measure these pressures, effort was maintained for at least 1 second. The highest positive MEP value and the lowest negative MIP value in three or more attempts were chosen. A one-minute break was taken between measurements so participants could recover to a normal breathing pattern [21].

\section{Peak cough flow}

The cough ability of the patient was measured using a peak flow meter (Mini Wright flow meter; Clement Clarke International Ltd., Essex, UK). The subjects breathed in as much as one could, and then coughed out forcefully and rapidly via mouthpiece in sitting position and holding one's nose. The maximal value among a total of 3 times was chosen [13].

\section{Data and statistical analysis}

All data was analyzed using IBM SPSS Statistics ver. 20.0 software (IBM Co., Armonk, NY, USA). The general characteristics of the subjects are expressed as mean and stand- 


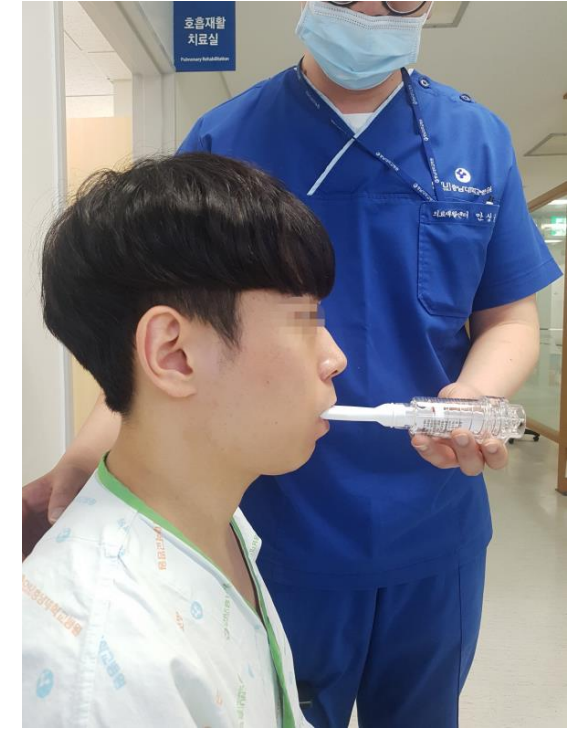

Figure 3. Inspiratory strengthening exercise.

ard deviation values through descriptive statistics. The chi-square test and independent sample t-test confirmed the homogeneity between the groups. The Shapiro-Wilk test was used for the normality analysis of all variables. The AST and the IST groups were compared using the paired t-test to compare before and after intervention, and the difference between groups was analyzed with the independent t-test. The statistical significance level was set as $\alpha=0.05$.

\section{Results}

A total of 24 CSCI patients participated in this study and were randomly assigned to either the AST group $(n=12)$ or the IST group $(n=12)$. Both general and medical subject characteristics in the AST group and IST group were all homogenous (Table 1).

For pulmonary function test, there was a significant improvement in both the AST and IST group in FVC and FEV1 values before and after intervention $(p<0.05)$. Post-test FVC and the mean change of FVC and FEV1 in AST was significantly higher than the IST group $(p>0.05)$. In the respiratory strength test, both training groups showed significant improvements in MIP and MEP after intervention $(p<0.05)$. The mean change of MIP in AST was significantly higher than the IST group $(p<0.05)$. To investigate the improvement of cough ability, the PCF test was used for evaluation. Both training groups showed significant improvements in PCF after intervention $(p<0.05)$. There was no significant difference between the two groups in the post-test and mean
Table 1. General characteristics of subjects $(\mathrm{N}=24)$

\begin{tabular}{lccr}
\hline \multicolumn{1}{c}{ Variable } & $\begin{array}{c}\text { AST group } \\
(\mathrm{n}=12)\end{array}$ & $\begin{array}{c}\text { IST group } \\
(\mathrm{n}=12)\end{array}$ & \multicolumn{1}{c}{$x^{2} / \mathrm{t}$} \\
\hline Sex (male/female $)$ & $10 / 2$ & $11 / 1$ & 0.381 \\
Age $(\mathrm{y})$ & $54.25(14.23)$ & $58.43(9.47)$ & -1.069 \\
Height $(\mathrm{cm})$ & $168.33(9.75)$ & $166.25(6.65)$ & 0.774 \\
Weight $(\mathrm{kg})$ & $63.37(12.34)$ & $58.43(9.47)$ & 1.101 \\
Onset $(\mathrm{d})$ & $30.50(8.30)$ & $34.08(10.00)$ & -0.955 \\
\hline
\end{tabular}

Values are presented as number only or mean (SD). AST: air stacking training, IST: incentive spirometry training.

Table 2. Comparative analysis of pulmonary function, respiratory strength, and peak cough flow $(\mathrm{N}=24)$

\begin{tabular}{cccc}
\hline Variable & AST group $(\mathrm{n}=12)$ & IST group $(\mathrm{n}=12)$ & $p$-value \\
\hline FVC $(\mathrm{L})$ & & & \\
Pre-test & $2.09(0.43)$ & $1.91(0.78)$ & 0.481 \\
Post-test & $2.63(0.37)$ & $2.13(0.73)$ & $0.048^{*}$ \\
$p$-value & $0.001^{*}$ & $0.015^{*}$ & \\
Change & $0.54(0.44)$ & $0.22(0.27)$ & $0.049^{*}$ \\
FEV1 (L) & & & \\
Pre-test & $1.68(0.47)$ & $1.51(0.70)$ & 0.509 \\
Post-test & $2.16(1.35)$ & $1.72(0.66)$ & 0.054 \\
$p$-value & $0.001^{*}$ & $0.032^{*}$ & \\
Change & $0.48(0.35)$ & $0.20(0.28)$ & $0.045^{*}$ \\
MEP (cmH $\left.H_{2} \mathrm{O}\right)$ & & & \\
Pre-test & $35.75(15.73)$ & $37.67(21.31)$ & 0.804 \\
Post-test & $39.00(16.38)$ & $41.58(20.87)$ & 0.739 \\
$p$-value & $0.028^{*}$ & $0.006^{*}$ & \\
Change & $3.25(4.45)$ & $3.92(4.06)$ & 0.705 \\
MIP (cmH $\left.{ }_{2} \mathrm{O}\right)$ & & & \\
Pre-test & $53.92(17.00)$ & $55.33(17.12)$ & 0.841 \\
Post-test & $60.75(18.02)$ & $57.92(17.60)$ & 0.701 \\
$p$-value & $0.001^{*}$ & $0.019^{*}$ & \\
Change & $6.75(4.94)$ & $2.58(3.29)$ & $0.024^{*}$ \\
PCF (L/min) & & & \\
Pre-test & $144(66.12)$ & $185.00(126.46)$ & 0.332 \\
Post-test & $163.33(70.75)$ & $200.83(121.17)$ & 0.365 \\
$p$-value & $0.002^{*}$ & $0.001^{*}$ & \\
Change & $21.67(14.67)$ & $15.83(13.11)$ & 0.316 \\
\hline
\end{tabular}

Values are presented as mean (SD).

AST: air stacking training, IST: incentive spirometry training, FVC: forced vital capacity, FEV1: forced expiratory volume one at second, MEP: maximal expiratory pressure, MIP: maximal inspiratory pressure, PCF: peak cough flow. ${ }^{*} p<0.05$.

change $(p>0.05$; Table 2$)$.

\section{Discussion}

CSCI patients have decreased pulmonary capacity and 
maximum cough rates due to weakened respiratory muscles [3]. Intercostal palsy, especially in CSCI patients, creates an unstable chest wall, and the pleura pressure, which is negative pressure during inhalation, causes the chest bone to go inward [22]. These mechanical imbalances and disadvantages lead to less efficient ventilation, increased respiratory activity, peripheral airway collapse, and micro-atelectasis [23]. Wong et al. [24] reported that aggressive respiratory therapy interventions to prevent respiratory complications in acute CSCI patients should begin immediately after injury, and much of the respiratory recovery has occurred within 7 days of respiratory therapy interventions. Previous studies examined the effect of AST on immediate coughing ability or applied as intervention to pulmonary function. This study was to investigate and evaluate the effects of rehabilitation program including AST conducted 3 sessions per week for 4 weeks, on pulmonary function, respiratory strength, and PCF in persons with CSCI, and obtained positive results.

FEV1 and FVC are important indicators of obstructive lung disease and restrictive lung disease. Since the strength of inspiratory muscle is reduced in CSCI patients, these lung function indicators are greatly reduced [3]. The results of this study showed that pulmonary function was significantly improved in the AST group $(p<0.05)$, and the mean change was significantly higher in the AST group than the IST group. These results are consistent with the findings of previous studies, which have significantly increased FVC after AST training in CSCI patients [25,26]. Neuromuscular disease patients with respiratory muscles weakness cannot breathe deeply. If chronic hypoventilation continues for a long time, the range of movement of the lung and chest wall gradually decreases, compliance of the lung and chest wall is reduced, the tissues of the chest wall becomes shortened, and the muscle becomes fibrotic [27]. The maximal insufflation capacity represents the maximum amount of air that can be injected into the lungs. The difference between maximum insufflation capacity and lung capacity is an indicator of the lung compliance [28]. Toussaint et al. [16] have reported an increase in maximum insufflation capacity after AST. In a study by Machado Diniz et al. [29], based on scintigraphic measurements with inhaled radioaerosol, it was shown that in healthy individuals, breath stacking allows more deposition of the radiopharmaceutical in the peripheral regions and in the lower third of the lung compared to incentive spirometry. Therefore, in this study, the AST group seems to have increased FVC and FEV1, which are in- dicators of pulmonary function, by increasing maximal insufflation capacity and eliminating atelectasis and sputum at the peripheral regions.

Inspiratory muscle strengthening training is used clinically as a common method to improve respiratory function and many studies have been conducted to investigate the effect of inspiratory muscle training in patients with spinal cord injury [30,31]. In this study, we performed inspiratory muscle strengthening exercises as a basic therapeutic exercise for both groups after intervention. The results of this study showed that respiratory strength was significantly improved in the AST group after intervention $(p<0.05)$, and the mean change of MIP was significantly higher in AST group than in IST group. In previous studies, the chest wall increased after air stacking in normal subjects and the effect of air stacking lasted for 30 minutes in the ALS patients $[32,33]$. Also high breathing volumes may have positive effects on the accessory respiratory muscles of the neck, which help to elevate the upper ribs, and therefore, increase the intra-thoracic area at the T4 level [34]. Therefore, this study seems to be effective when the inspiratory muscle training is performed because it affects the force-length relationship of the muscle after AST. The expiration action of the chest and abdomen in SCI patients is primarily a passive action, which is dependent upon the recoil of the inflated chest due to paralysis of the intercostal and abdominal muscles [35]. Both groups in this study seem to have increased MEP due to increases in lung recoil ability via increases in lung capacity.

PCF is used to assess coughing ability due to weakened respiratory muscle strength in patients with neuromuscular disease [36]. Persons with CSCI and higher level injury paraplegia showed a significant reduction in cough efficiency due to loss of function of expiratory muscles such as intercostal muscles, anterior abdominal muscles of the abdomen, and sternal epidermis after spinal cord injury [37]. Previous studies have shown that PCF is increased and MIP is also increased by applying AST to CSCI patients [13,17]. In this study, PCF was significantly increased in both groups. The inspiratory muscle force involved in the inspiratory phase was not as large as the expiratory muscle force but had a significant correlation with PCF [38]. Because both groups performed inspiratory muscle strengthening exercise after intervention, PCF was also increased as MIP increased. However maximal insufflation capacity contributes $44 \%$, the expiratory reserve volume $13 \%$ and the MEP $2 \%$ in PCF increase in patients with neuromuscular diseases [11]. As mentioned above, AST is expected to contribute more to 
PCF because it directly increases and maintains maximal insufflation capacity.

According to this study, AST is effective in improving pulmonary function, respiratory muscle strength, and PCF in persons with CSCI. These results suggest that AST should be included in respiratory rehabilitation programs to improve coughing ability, lung function, and respiratory muscle strength.

\section{Conflict of Interest}

The authors declared no potential conflicts of interest with respect to the authorship and/or publication of this article.

\section{References}

1. Brown R, DiMarco AF, Hoit JD, Garshick E. Respiratory dysfunction and management in spinal cord injury. Respir Care 2006;51:853-68; discussion 869-70.

2. DeVivo MJ, Krause JS, Lammertse DP. Recent trends in mortality and causes of death among persons with spinal cord injury. Arch Phys Med Rehabil 1999;80:1411-9.

3. Baydur A, Adkins RH, Milic-Emili J. Lung mechanics in individuals with spinal cord injury: effects of injury level and posture. J Appl Physiol (1985) 2001;90:405-11.

4. Sipski ML, Richards JS. Spinal cord injury rehabilitation: state of the science. Am J Phys Med Rehabil 2006;85:310-42.

5. Maloney FP. Pulmonary function in quadriplegia: effects of a corset. Arch Phys Med Rehabil 1979;60:261-5.

6. Schilero GJ, Spungen AM, Bauman WA, Radulovic M, Lessera M. Pulmonary function and spinal cord injury. Respir Physiol Neurobiol 2009;166:129-41.

7. Manning H, McCool FD, Scharf SM, Garshick E, Brown, R. Oxygen cost of resistive-loaded breathing in quadriplegia. $\mathrm{J}$ Appl Physiol (1985) 1992;73:825-31.

8. Bhaskar KR, Brown R, O'Sullivan DD Melia S, Duggan M, Reid L. Bronchial mucus hypersecretion in acute quadriplegia. Macromolecular yields and glycoconjugate composition. Am Rev Respir Dis 1991;143:640-8.

9. Jaeger RJ, Turba RM, Yarkony GM, Roth EJ. Cough in spinal cord injured patients: comparison of three methods to produce cough. Arch Phys Med Rehabil 1993;74:1358-61.

10. Kang SW, Rha DW, Ryu HH, Kang YS, Kang YJ, Moon JH. Analysis of pulmonary mechanics and the factors for coughing in Duchenne muscular dystrophy. J Korean Acad Rehabil Med 2003;27:43-8.

11. Trebbia G, Lacombe M, Fermanian C, Falaize L, Lejaille M, Louis A, et al. Cough determinants in patients with neuromuscular disease. Respir Physiol Neurobiol 2005;146:291-300.

12. Scanlan C, Myslinski MJ. Bronchial hygiene therapy. In: Scanlan CL, Stoller JK, Wilkins RL, editors. Egan's fundamentals of respiratory care. 7th ed. St. Louis: Mosby; 1999. p. 792-3.
13. Kang SW, Cho DH, Lee SC, Moon JH, Park YG, Song NK, et al. Clinical implication of air stacking exercise in patients with neuromuscular diseases. J Korean Acad Rehabil Med 2007;31:346-50.

14. Liszner K, Feinberg M. Cough assist strategy for pulmonary toileting inventilator-dependent spinal cord injured patients. Rehabil Nurs 2006;31:218-21.

15. Rafiq MK, Bradburn M, Proctor AR, Billings CG, Bianchi S, McDermott CJ, el al. A preliminary randomized trial of the mechanical insufflator-exsufflator versus breath-stacking technique in patients with amyotrophic lateral sclerosis. Amyotroph Lateral Scler Frontotemporal Degener 2015;16:448-55.

16. Toussaint M, Pernet K, Steens M, Haan J, Sheers N. Cough augmentation in subjects with Duchenne muscular dystrophy: comparison of air stacking via a resuscitator bag versus mechanical ventilation. Respir Care 2016;61:61-7.

17. Torres-Castro R, Vilaró J, Vera-Uribe R, Monge G, Avilés P, Suranyi C. Use of air stacking and abdominal compression for cough assistance in people with complete tetraplegia. Spinal Cord 2014;52:354-7.

18. Alaparthi GK, Augustine AJ, Anand R, Mahale A. Comparison of diaphragmatic breathing exercise, volume and flow incentive spirometry, on diaphragm excursion and pulmonary function in patients undergoing laparoscopic surgery: a randomized controlled trial. Minim Invasive Surg 2016. doi: 10.1155/2016/ 1967532.

19. Chuang HY, Chang HY, Fang YY, Guo SE. The effects of threshold inspiratory muscle training in patients with chronic obstructive pulmonary disease: a randomised experimental study. $\mathrm{J}$ Clin Nurs 2017;26:4830-8.

20. Kim MJ, Park DS. The effect of Schroth's three-dimensional exercises in combination with respiratory muscle exercise on Cobb's angle and pulmonary function in patients with idiopathic scoliosis. Phys Ther Rehabil Sci 2017;6:113-9.

21. Hwang YI, Kim KS. Comparison of the effects of different-sized airways in inspiratory trainers on maximal inspiratory pressure and rating of perceived exertion scale in healthy young people. Phys Ther Rehabil Sci 2018;7:18-22.

22. Lucke KT. Pulmonary management following acute SCI. J Neurosci Nurs 1998;30:91-104.

23. Fishburn MJ, Marino RJ, Ditunno JF Jr. Atelectasis and pneumonia in acute spinal cord injury. Arch Phys Med Rehabil 1990; 71:197-200.

24. Wong SL, Shem K, Crew J. Specialized respiratory management for acute cervical spinal cord injury: a retrospective analysis. Top Spinal Cord Inj Rehabil 2012;18:283-90.

25. Kim MK, Cho MS, Hwang BG. The efficacy of pulmonary rehabilitation using air stacking exercise in cervical cord injured patients. J Korean Soc Phys Med 2010;5:597-604.

26. Jeong JH, Yoo WG. Effects of air stacking on pulmonary function and peak cough flow in patients with cervical spinal cord injury J Phys Ther Sci 2015;27:1951-2.

27. Estenne M, Gevenois PA, Kinnear W, Soudon P, Heilporn A, De Troyer A. Lung volume restriction in patients with chronic respiratory muscle weakness: the role of microatelectasis. Thorax 1993;48:698-701.

28. Bach JR, Smith WH, Michaels J, Saporito L, Alba AS, Dayal R, et al. Airway secretion clearances by mechanical exsufflation for post-poliomyelitis ventilator-assisted individuals. Arch Phys 
Med Rehabil 1993;74:170-7.

29. Machado Diniz D, Dornelas de Andrade A, Lopes A, Mendes M, Bellaguarda E, Macena RHM, et al. Lung deposition pattern of inhaled radiotracers during the Breath-Stacking and incentive spirometry techniques. Eur J Respir Dis 2004;24:407s.

30. Brooks D, O’Brien K, Geddes EL, Crowe J, Reid WD. Is inspiratory muscle training effective for individuals with cervical spinal cord injury? A qualitative systematic review. Clin Rehabil 2005;19:237-46

31. Van Houtte S, Vanlandewijck Y, Kiekens C, Spengler CM, Gosselink R. Patients with acute spinal cord injury benefit from normocapnic hyperpnoea training. J Rehabil Med 2008;40:119-25.

32. Sarmento A, de Andrade AF, Lima ÍN, Aliverti A, de Freitas Fregonezi GA, Resqueti VR. Air stacking: a detailed look into physiological acute effects on cough peak flow and chest wall volumes of healthy subjects. Respir Care 2017;62:432-43.

33. Cleary S, Misiaszek JE, Kalra S, Wheeler S, Johnston W. The effects of lung volume recruitment on coughing and pulmonary function in patients with ALS. Amyotroph Lateral Scler Fronto- temporal Degener 2013;14:111-5.

34. Mueller G, Hopman MT, Perret C. Comparison of respiratory muscle training methods in individuals with motor and sensory complete tetraplegia: a randomized controlled trial. J Rehabil Med 2013;45:248-53.

35. Kelly BJ, Luce JM. The diagnosis and management of neuromuscular diseases causing respiratory failure. Chest 1991;99: 1485-94.

36. Ishikawa Y, Bach JR, Komaroff E, Miura T, Jackson-Parekh R. Cough augmentation in Duchenne muscular dystrophy. Am J Phys Med Rehabil 2008;87:726-30.

37. Fujiwara T, Hara Y, Chino N. Expiratory function in complete tetraplegics: study of spirometry, maximal expiratory pressure, and muscle activity of pectoralis major and latissimus dorsi muscles. Am J Phys Med Rehabil 1999;78:464-9.

38. Park JH, Kang SW, Lee SC, Choi WA, Kim DH. How respiratory muscle strength correlates with cough capacity in patients with respiratory muscle weakness. Yonsei Med J 2010;51:392-7. 